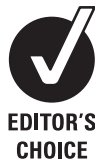

${ }^{1}$ Aspetar, Qatar Orthopaedic and Sports Medicine Hospital, Doha, Oatar; ${ }^{2}$ Anglesea Clinic, Hamilton, New Zealand: ${ }^{3}$ South Sydney Sports Medicine Centre, Sydney, Australia; ${ }^{4}$ University of New South Wales

Correspondence to: Dr J A Paoloni, Aspetar, Oatar Orthopaedic and Sports

Medicine Hospital, PO Box 29222, Doha, Datar; pao_26@ hotmail.com

Accepted 16 May 2009 Published Online First 21 June 2009

\title{
Non-steroidal anti-inflammatory drugs in sports medicine: guidelines for practical but sensible use
}

\author{
J A Paoloni, ${ }^{1}$ C Milne, ${ }^{2}$ J Orchard, ${ }^{3,4}$ B Hamilton ${ }^{1}$
}

ABSTRACT

Introduction: Non-steroidal anti-inflammatory drugs (NSAID) are commonly used in sports medicine. NSAID have known anti-inflammatory, analgesic, antipyretic and antithrombotic effects, although their in-vivo effects in treating musculoskeletal injuries in humans remain largely unknown. NSAID analgesic action is not significantly greater than paracetamol for musculoskeletal injury but they have a higher risk profile, with side-effects including asthma exacerbation, gastrointestinal and renal sideeffects, hypertension and other cardiovascular diseases. Discussion: The authors recommend an approach to NSAID use in sports medicine whereby simple analgesia is preferentially used when analgesia is the primary desired outcome. However, based both on the current pathophysiological understanding of most injury presentations and the frequency that inflammation may actually be a component of the injury complex, it is premature to suppose that NSAID are not useful to the physician managing sports injuries. The prescribing of NSAID should be cautious and both situation and pathology specific. Both dose and duration minimisation should be prioritised and combined with simple principles of protection, rest, ice, compression, elevation (PRICE), which should allow NSAID-sparing. NSAID use should always be coupled with appropriate physical rehabilitation.

Conclusion: NSAID are probably most useful for treating nerve and soft-tissue impingements, inflammatory arthropathies and tenosynovitis. They are not generally indicated for isolated chronic tendinopathy, or for fractures. The use of NSAID in treating muscle injury is controversial. Conditions in which NSAID use requires more careful assessment include ligament injury, joint injury, osteoarthritis, haematoma and postoperatively.

Non-steroidal anti-inflammatory drugs (NSAID) are commonly utilised in sports medicine. NSAID have known anti-inflammatory, analgesic, antipyretic and antithrombotic effects, ${ }^{1}$ although their in-vivo effects in treating musculoskeletal injuries in humans remain largely unknown. NSAID analgesic action does not appear to be significantly greater than paracetamol for musculoskeletal injury ${ }^{2}$ but they have a higher risk profile, with side-effects including asthma exacerbation, gastrointestinal and renal side-effects, hypertension and other cardiovascular diseases. Evidence-based working groups on pain management recommend using regular paracetamol as first-line treatment for acute $^{3}$ and chronic musculoskeletal pain. ${ }^{4}$ Furthermore, intramuscular NSAID have additional risks with fluctuant drug levels, infection and muscle necrosis such as in Nicolau syndrome. ${ }^{5}$

NSAID work via cyclooxygenase (COX) inhibition, thus blocking prostaglandin production from arachadonic acid. Prostaglandin inhibition will decrease the cascading inflammatory response, but will also lead to increased leucotriene production through the "overflow" pathway for arachadonic acid. ${ }^{6}$ COX-2 inhibitors are a subclass of NSAID that specifically block the COX-2 enzyme, and subsequently have fewer gastrointestinal sideeffects and renal side-effects but at a cost of an increased risk of cardiovascular side-effects. NSAID in sports medicine practice are delivered as topical, oral, intramuscular or, less commonly, intravenous preparations. Daily NSAID use in the general population is $1-4 \%^{78}$ and in elite athletes at Olympic games or during Fédération Internationale de Football Association World Cup football tournaments, the reported use of NSAID is as high as 25$35 \% .{ }^{9-11}$ Given their availability, the use of NSAID to treat sporting injury in the general population is probably similar to that seen in elite sporting populations. As medical practitioners, sports physicians are obliged by the Hippocratic oath to "first do no harm", and this discussion paper will attempt to address the utilisation of NSAID use in musculoskeletal injury pragmatically.

\section{RATIONAL USE OF NSAID IN SPORTS MEDICINE}

Recent well-publicised adverse events surrounding COX-2 anti-inflammatories, in combination with an increased understanding of soft-tissue injury pathophysiology, have resulted in NSAID use in sports medicine being challenged. ${ }^{12}$ While recognising that NSAID utilisation rates have potentially been too high in the past, ${ }^{13}$ we caution against the attitude of shunning NSAID use as they are potentially helpful in many common sports medicine scenarios. Early functional mobilisation is a key component to the rehabilitation and early return to sporting activity following many injuries, and pain management is integral to this. ${ }^{14}$ In addition to their well-documented anti-inflammatory action, NSAID are known to be moderately potent analgesics, ${ }^{1}$ and therefore when prescribing, one must consider whether they are being used for analgesic, anti-inflammatory or a combined benefit.

Acute muscle and chronic tendon injuries are two areas in which great progress has been made in recent years. ${ }^{15} 16$ While in tendon injuries it is established that inflammation is not a prerequisite for pain in chronic tendinopathies, the opposite appears to be true in the early phases of muscle strain injury, when inflammation is present and its modulation may be critical. ${ }^{17-19}$ Regarding muscle strain injury, concerns of increased bleeding from the anti-platelet effect of COX-1 inhibition of thromboxane A2 had traditionally led to NSAID use being a relative contraindication in the early 
Table 1 Author's pragmatic guidelines for NSAID use

\begin{tabular}{ll}
$\begin{array}{l}\text { Conditions in which NSAID will tend to be most useful (but should be } \\
\text { avoided if the patient is at high risk of side effects) }\end{array}$ & $\begin{array}{l}\text { Impingement conditions (nerve or soft-tissue } \\
\text { impingement) } \\
\text { Tenosynovitis } \\
\text { Inflammatory arthropathy }\end{array}$ \\
$\begin{array}{l}\text { Conditions in which NSAID use might be considered based on clinical } \\
\text { findings }\end{array}$ & $\begin{array}{l}\text { Ligament and joint sprains } \\
\text { Osteoarthritis and other degenerative joint conditions } \\
\text { Haematomas } \\
\text { Postoperatively } \\
\text { The value of NSAID remains controversial and should be used with }\end{array}$ \\
$\begin{array}{l}\text { Contion } \\
\text { may compromise healing }\end{array}$ & $\begin{array}{l}\text { Muscle strains } \\
\text { Isolated chronic tendinopathies (without impingement) }\end{array}$ \\
\hline
\end{tabular}

NSAID, non-steroidal anti-inflammatory drug.

phases, but with the advent of specific COX-2 inhibitor formulations, this became less relevant. Inflammation initiates macrophage action, with subsequent phagocytosis of necrotic tissue and stimulation of new capillary formation, vital aspects of muscle regeneration. However, inflammation also causes oedema with resultant anoxia and further cell death. The extent of the early inflammatory response after injury may be excessive. ${ }^{20}$ Modulation of this inflammatory response with low-dose NSAID in the subacute phase, after the early macrophage-mediated processes have begun, may have beneficial effects ${ }^{2122}$ by limiting oedema, without affecting satellite cell and fibroblast proliferation, ${ }^{23}$ myotube and capillary regeneration ${ }^{23}$ or subsequently tensile and contractile strength..$^{24}$ By contrast, however, impediment of regeneration and increased fibrosis in the latter stages of muscle healing may suggest that NSAID use is contraindicated once regenerative processes have begun. ${ }^{23}{ }^{25}$ Due to the potentially critical role of the COX-2 enzyme in muscle regeneration and the cardiovascular risk profile, COX-2 inhibitors should not generally be used to treat muscle injury. ${ }^{25} 26$

In contrast to muscle strain injuries, the benefits of using NSAID in eccentrically induced muscle soreness is well established. ${ }^{27}$ The use of NSAID patches have recently been shown to be beneficial in the early management of contusion type injuries, ${ }^{28}$ and the risk of myositis ossificans has been shown to be reduced post-surgically by the expedient use of NSAID. ${ }^{29}$ NSAID are thus not contraindicated in muscle injury per se, but should be used with consideration of the specific pathology being treated.

The majority of literature surrounding tendinopathy is specific to chronic tendinopathy. The histopathology of tendinopathy is typically degenerative, with an absence of inflammatory cells or biochemical markers of inflammation..$^{30}$ The pain of tendinopathy thus not associated with bursitis, tenosynovitis or other inflammatory comorbity could be rationally treated with paracetamol rather than NSAID. Whereas tendinopathies with an associated co-morbid inflammatory component may benefit from NSAID, it is also not uncommon for team physicians at the elite level to see the first presentation of a tendinopathy within 1-2 days of pain onset. In this situation, it may not be unreasonable to attempt to treat any suspected tendon or paratendon inflammatory-mediated symptoms with NSAID.

Ankle sprains are a common presentation to sports medicine practitioners, with numerous potential pathological components including ligament injury, intra-articular synovitis and chondral damage. COX-2 inhibitors have been shown to impair healing in ligament $\mathrm{t}^{31}$ and bone ${ }^{32}$ and probably should not be use to treat acute joint injuries. While several studies have shown enhanced functional recovery after ankle sprain when NSAID were employed in addition to standard rehabilitation techniques, ${ }^{33}{ }^{34}$ it is suggested that while the decreased pain may allow an earlier return to army training, ultimately they have increased instability and a decreased range of motion. ${ }^{34}$ This may suggest that NSAID are having both an analgesic and antisynovitic benefit, rather than any effect on ligament healing. ${ }^{34}$ However, to uniformly exclude NSAID from the treatment armoury of ankle sprains would appear premature, based on the knowledge available, and when the predominant functional limitation may be synovitis.

Inflammatory conditions such as rheumatoid arthritis clearly benefit from NSAID, and many of the co-morbities of such conditions, in particular inflammatory bursitis, intra-articular synovitis and tenosynovitis, are common sporting presentations to the sports physician. A trial of oral NSAID before more aggressive interventions is considered acceptable practice and should not be excluded.

\section{What this study adds}

We recommend considering regular paracetamol as first-line treatment for acute and chronic musculoskeletal pain, due to comparable analgesic efficacy with NSAID but a lower sideeffect profile.

- Evidence suggests that NSAID are useful in treating inflammatory pathologies such as tenosynovitis and softtissue impingement, but not conditions such as chronic tendinopathies and fractures.

- The use of NSAID in treating muscle injury remains controversial.

\section{What is already known on this topic}

NSAID are commonly used in sports medicine, and have antiinflammatory, analgesic and antithrombotic effects, but their invivo effects in treating musculoskeletal injuries in humans remain uncertain. 


\section{CONCLUSION}

The use of NSAID for sports injuries continues to be controversial, particularly in the treatment of muscle and ligament injuries. Conclusive support for NSAID use is limited due to numerous animal studies, but few randomised clinical trials in humans. Sports medicine encompasses a broad spectrum of pathology and clinical situations. The authors recommend an approach whereby simple analgesia is preferentially used when analgesia is the primary desired outcome. However, based both on the current pathophysiological understanding of most injury presentations, and the frequency that inflammation may actually be a component of the injury complex, it is premature to suppose that NSAID are not useful to the physician managing sports injuries. The prescribing of NSAID should be cautious, and both situation and pathology specific. Both dose and duration minimisation should be prioritised and combined with simple principles of protection, rest, ice, compression, elevation (PRICE), which should allow NSAID-sparing. NSAID use should always be coupled with appropriate physical rehabilitation. There are many barriers to physician adherence to NSAID utilisation guidelines, including personal experience, the perceived limited validity of guidelines and the limited applicability of guidelines for specific patients. ${ }^{35}$ This needs consideration when recommending medication use. Given the current evidence and current understanding of injury pathology, we have formulated pragmatic clinical guidelines for oral NSAID use in sports injuries (table 1).

Competing interests: Declared. One author has previously received once-off funding from a drug company, Glaxo Smith Klein, but there are no current competing interests of any authors.

Provenance and peer review: Not commissioned; externally peer reviewed.

\section{REFERENCES}

1. Martin J, ed. Musculoskeletal and joint diseases. British National Formulary. London: British Medical Association and the Royal Pharmaceutical Society of Great Britain, 2008:534-64.

2. Woo WWK, Man S-Y, Lam P, et al. Randomized double-blind trial comparing oral paracetamol and oral nonsteroidal anti-inflammatory drugs for treating pain after musculoskeletal injury. Ann Emerg Med 2005;46:352-61.

3. Australian Acute Musculoskeletal Pain Guidelines Group (AAMPGG) Evidence based management of acute musculoskeletal pain, 2004. Australian Academic Press. Brisbane. http://www.nhmrc.gov.au (accessed April 2009)

4. Schnitzer TJ. Update on guidelines for the treatment of chronic musculoskeletal pain. Clin Rheumatol 2006;25(Suppl 1):S22-9.

5. Hamilton BH, Fowler $\mathrm{P}$, Galloway $\mathrm{H}$, et al. Nicolau syndrome in an athlete following intra-muscular diclofenac injection. Acta Orthop Belg 2008;74:860-4.

6. Beers MH, Berkow R. The Merck manual of diagnosis and therapy, 17th edn. Whitehouse Station, New Jersey, USA: Merck Research Laboratries, 1999:418-20.

7. Barozzi N, Tett SE. Non-steroidal anti-inflammatory drugs, cyclooxygenase-2 inhibitors and paracetamol use in Queensland and in the whole of Australia. BMC Health Services Res 2008;8:196.

8. Leufkens HG, Ameling CB, Hekster YA, et al. Utilization patterns of non-steroidal antiinflammatory drugs in an open Dutch population. Pharm Weekb/ Sci 1990;12:97-103.
9. Huang SH, Johnson K, Pipe AL. The use of dietary supplements and medications by Canadian athletes at the Atlanta and Sydney Olympic Games. Clin J Sport Med 2006;16:27-33

10. Corrigan B, Kazlauskas R. Medication use in athletes selected for doping control at the Sydney Olympics (2000). Clin J Sport Med 2003;13:33-40.

11. Tscholl $\mathbf{P}$, Junge A, Dvorak J. The use of medication and nutritional supplements during FIFA World Cups 2002 and 2006. Br J Sports Med 2008;42:725-30.

12. Magra M, Maffulli N. Nonsteroidal antiinflammatory drugs in tendinopathy. Friend or foe. Clin J Sport Med 2006;16:1-3.

13. Gerrard DF. Renal abuse from non-steroidal, anti-inflammatory agents in sport. NZ Med J 1998;111:107-8.

14. Drezner J. Practical management: hamstring muscle injuries. Clin J Sport Med 2003:13:48-52.

15. Huard J, Li Y, Fu F. Muscle injuries and repair: current trends in research. J Bone Joint Surg 2002;84-A:822-33.

16. Ashe M, Khan KM, Maffulli N, et al. Pathology of chronic Achilles-tendon injuries in athletes. Int SportMed J 2001;2:1-11.

17. Toumi H, Best TM. The inflammatory response: friend or enemy for muscle injury? Br J Sport Med 2003;37:284-6.

18. Brickson S, Hollander J, Corr DT, et al. Oxidant production and immune response after stretch injury in skeletal muscle. Med Sci Sport Exerc 2001;33:2010-15.

19. Best TM, Fiebig R, Corr DT, et al. Free radical activity, antioxidant enzyme, and glutathione changes with muscle stretch injury in rabbits. J Appl Physiol 1999;87:74-82

20. Jarvinen TAH, Kaariainen $\mathrm{M}$, Jarvinen $\mathrm{M}$, et al. Muscle strain injuries. Curr Opin Rheumatol 2000:12:155-61.

21. Brickson S, Ji LL, Schell K, et al. M1/70 attenuates blood-borne neutrophil oxidants, activation, and myofiber damage following stretch injury. J Appl Physiol 2003:95:969-76.

22. Pizza FX, Peterson JM, Baas JH, et al. Neutrophils contribute to muscle injury and impair its resolution after lengthening contractions in mice. J Physiol 2005:562:899-913.

23. Thorsson 0, Rantanen J, Hurme $\mathrm{T}$, et al. Effects of nonsteroidal antiinflammatory medication on satellite cell proliferation during muscle regeneration. Am J Sport Med 1998;26:172-6.

24. Obremsky WT, Seaber AV, Ribbeck BM, et al. Biomechanical and histological assessment of controlled muscle strain injury treated with piroxicam. Am J Sports Med 1994;22:558-61

25. Shen W, Li Y, Tang Y, et al. NS-398, a cyclooxygenase-2-specific inhibitor, delays skeletal muscle healing by decreasing regeneration and promoting fibrosis. Am J Patho 2005; 167:1105-17

26. Bondesen BA, Mills ST, Kegley KM, et al. The COX-2 pathway is essential during early stages of skeletal muscle regeneration. Am J Physiol Cell Physiol 2004:287:C475-83.

27. Dudley GA, Czerkawski J, Meinrod A, et al. Efficacy of naproxen sodium for exercise induced dysfunction muscle injury and soreness. Clin J Sport Med 1997:10:3-10.

28. Predel HG, Koll R, Pabst H, et al. Diclofenac patch for topical treatment of acute impact injuries: a randomised, double blind, placebo controlled, multicentre study. Br J Sport Med 2004;38:318-23.

29. Fijn R, Koorevaar RT, Brouwers RBJ. Prevention of heterotrophic ossification after hip replacement with NSAIDs. Pharm World Sci 2003:25:138-45.

30. Alfredson H. The chronic painful Achilles and patellar tendon: research on basic biology and treatment. Scand J Med Sci Sports 2005;15:252-9.

31. Elder CL, Dahners LE, Weinhold PS. A cyclooxygenase-2 inhibitor impairs ligament healing in the rat. Am J Sports Med 2001;29:801-5.

32. Simon AM, Manigrasso MB, O'Connor JP. Cyclo-oxygenase 2 function is essential for bone fracture healing. J Bone Miner Res 2002;17:963-76.

33. Moran M. Double-blind comparison of diclofenac potassium, ibuprofen and placebo in the treatment of ankle sprains. J Int Med Res 1991;19:121-30.

34. Slatyer MA, Hensley MJ, Lopert R. A randomized controlled trial of piroxicam in the management of acute ankle sprain in Australian regular army recruits. Am J Sports Med 1997:25:533-44.

35. Cavazos JM, Naik AD, Woofter A, et al. Barriers to physician adherence to nonsteroidal anti-inflammatory guidelines: a qualitative study. Aliment Pharmacol Ther 2008:28:789-98. 